Produto \& Produção, vol.12, n.1, p. 20 - 41, fev. 2011

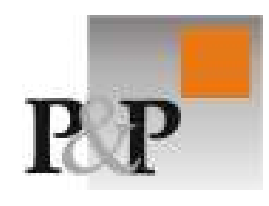

\title{
Modelo de Quatro Forças para Alavancagem da Sustentabilidade em Empresas do Setor de Construção Civil
}

Pedrita Dantas Gabriele

Mestranda em Engenharia de Produção pela UFF

Danielle Dias Ricardo

Mestranda em Engenharia de Produção pela UFF

Alice Monnerat Erthal Levi

Mestranda em Engenharia de Produção pela UFF

Alexandre Cesar Salem e Silva

Mestranda em Engenharia de Produção pela UFF

Janaína Oliveira Tannus

Engenharia de Produção UFF

Gilson Brito A. Lima

UFF

Jose Rodrigues de Farias Filho

UFF

O presente trabalho aplica o Modelo de Quatro Forças para analisar como transformar o desenvolvimento de uma organização de um modelo insustentável para um modelo sustentável, focado no aspecto ambiental, mas sem desconsiderar os aspectos econômico e social. Para seu desenvolvimento, foi realizada pesquisa bibliográfica e exploratória em um estudo de caso sobre a análise de maturidade em sustentabilidade de uma empresa do setor de construção civil, como diagnóstico da situação atual da empresa. Foram utilizadas as análises obtidas no estudo de caso para aplicação do Modelo de Quatro Forças e, como resultado, foi elaborado uma proposta de priorização das ações de melhoria para tornar o desenvolvimento da empresa sustentável.

Palavras-chave: Modelo de Quatro Forças, Sustentabilidade, Construção Civil.

This work applies the Four Forces Model to examine how to transform the development of an organization from an unsustainable model to a sustainable model, focused on the environmental aspect, without leaving aside the economic and social aspects. For its development, a bibliographic research was conducted in an exploratory case study on the maturity analysis of sustainability in a company of construction sector, in order to diagnose the company current situation. The analysis obtained in the case study was used for implementation of the Four Forces Model and, as a result, a plan of action was proposed to promote the sustainable development. 
Keywords: Four Forces Model, Sustainability, Construction sector

\section{INTRODUÇÃO}

O conceito de desenvolvimento sustentável é historicamente relacionado somente aos aspectos ambientais, mas não só disso depende a sustentabilidade das empresas. Os gestores precisam complementar este conceito com os aspectos econômicos e sociais, aspectos estes que fazem parte do tripé da sustentabilidade, também chamado de Triple Bottom Line, o qual aborda o desenvolvimento sustentável de forma sistemática através da interação entre seus pilares. Mesmo só considerando o aspecto ambiental, muitas empresas aceitam o fato de seu negócio produzir rejeitos e subprodutos sendo parte inerente da produção. Com este pensamento, as ações são voltadas somente em como realizar o descarte deste material. Mas com o crescimento da produção, o descarte deste tipo de subproduto se tornou um problema cada vez maior, pois a natureza possui uma capacidade limitada de extração de recursos e de absorção de resíduos. De acordo com Gandhi (2006), já em 1970 a capacidade per capita de terra e água para suportar o consumo de recursos e o descarte por pessoa atingiu a marca de sustentabilidade pela primeira vez e manteve-se insustentável desde então. Os principais responsáveis pela degradação do meio ambiente são: industrialização, crescimento da população, mudanças no consumo, contínuo esgotamento de recursos não renováveis.

A partir de certo limite de inconsciência sustentável, as empresas precisam lidar com problemas cada vez maiores para o descarte dos subprodutos, o que envolve custos cada vez mais elevados e maiores impactos na sociedade, pois a natureza está sendo degradada, comprometendo o atendimento às necessidades das gerações seguintes (Brito, 2010).

Apesar da necessidade de um desenvolvimento sustentável (DS), há ainda uma lacuna no conhecimento ou uma interpretação parcial dos conceitos relacionados ao DS, de modo que as organizações não estão preparadas para implementar novas práticas de gestão. Além disso, não existem ferramentas que auxiliem as empresas a analisar sua situação atual, identificar suas necessidades e implementar as mudanças necessárias para o atingimento de um desenvolvimento sustentável.

Outras pressões externas estão atuando nas empresas para mudar seu modo de desenvolvimento insustentável para um desenvolvimento sustentável, como por exemplo, a sociedade, o governo, os consumidores. Os gestores não podem ter a visão de que essa mudança trará custos para a organização, pois desta forma as transformações não ocorrerão. As mudanças precisam ser analisadas sob a ótica de redução de custos, como por exemplo, a reutilização dos resíduos da produção e a diminuição do desperdício.

De acordo com a Figura 1, para a aplicação de um modelo de gestão empresarial para a sustentabilidade devem ser considerados desde referenciais globais de sustentabilidade até a análise dos resultados internos de forma balanceada entre os aspectos econômicos, sociais e ambientais. 


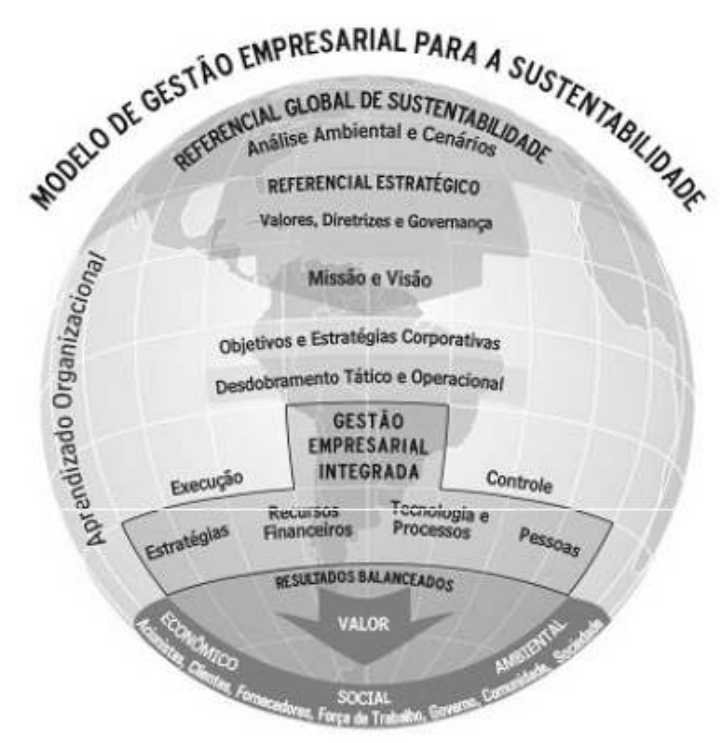

Figura 1 - Modelo de Gestão Empresarial para a Sustentabilidade (Fonte: COPEL, 2010)

A revisão da literatura aponta uma vasta produção acadêmica sobre temas no topo da Figura 1, ou seja, sobre questões gerenciais da sustentabilidade em nível estratégico. Porém, existe uma carência de ferramentas de gestão que desdobrem esses conceitos em nível tático e operacional de forma a transformar um ambiente insustentável de uma empresa em um ambiente sustentável.

Por isso, este artigo tem como objetivo desenvolver uma metodologia para levantar e priorizar ações de melhoria que possam tornar o ambiente de uma empresa insustentável em um ambiente sustentável. Para tal será desenvolvida um método com base nas premissas adotadas pelo Modelo Quatro Forças de Gandhi (2006) em conjunto com uma ferramenta de análise do nível de maturidade da sustentabilidade de uma empresa, que fez parte de um esforço anterior de alguns dos autores do presente artigo. No final, será aplicado um estudo de caso para validar a aplicabilidade da metodologia para o setor estudado.

Por fim, cabe ressaltar que a ferramenta atende às necessidades de empresas do setor de construção civil, necessitando de revisões por especialistas no caso de aplicação em outros setores. Além disso, devido as suas especificidades de aplicação, a ferramenta é proposta para pequenas e médias empresas desse setor.

\section{REFERENCIAL TEORICO}

\subsection{Contextualização do Desenvolvimento Sustentável}

Em 1972, o livro "Limits to Growth" (Meadows, 1972) já argumentava que as taxas de uso dos recursos naturais finitos da Terra não poderiam continuar por tempo indefinido. Essa posição dava voz a uma posição de uma comunidade fundada em 1968, denominada Clube de Roma, cuja preocupação era discutir os problemas cruciais para o futuro da humanidade referentes ao desenvolvimento em 
setores tais como o de energia, poluição, saneamento, saúde, meio-ambiente, tecnologia e crescimento populacional.

Na década seguinte à do relatório do Clube de Roma (Meadows, 1972), entre 1983 e 1987, a Organização das Nações Unidas, criou a Comissão Mundial sobre Meio Ambiente e Desenvolvimento. Esta comissão publicou o Relatório Brundtland, ou Relatório "Nosso Futuro Comum", em que se obteve o primeiro conceito formal de "sustentabilidade", que ficou definida como a "capacidade de prover o crescimento e suprir as necessidades da geração presente sem afetar a habilidade das gerações futuras de suprir as suas". Este documento foi alvo de estudos e propostas multidisciplinares, cada qual interessada em tangibilizar o conceito para determinada área de interesse. Dentre os estudos originários do conceito de sustentabilidade, destaca-se o do triple bottom line ou tripé da sustentabilidade. Ele reúne não somente os aspectos econômicos, como também sua interação com aspectos ambientais e sociais.

Foi somente em 1992 que o termo 'desenvolvimento sustentável' ganhou força e aderência dos principais interessados. Neste ano, foi realizada a conferência Eco 92 - United Nations Conference on Environment and Development - UNCED, conferência que confirmou a preocupação global com o tema, através da Agenda 21 (UNCED, 1992), documento no qual as nações concordaram em criar uma parceira global, como forma de engajar e estimular um diálogo contínuo, centrado na busca de um novo modelo econômico mais eficiente e equitário.

Diferentes setores da economia iniciaram o trabalho de interpretar a Agenda 21, trazendo especificidades de sua área, ao compromisso estabelecido durante a Eco-92. A construção civil, setor trabalhado neste documento, enumera três relatórios como principais no seu setor: Agenda Habitat II de 1996, CIB Agenda 21 on Sustainable Construction em 1999 e Agenda 21 for Sustainable Constructions in Developing Countries de 2002. (Silva, 2003).

Enfatizando o papel atual da construção civil no contexto da sustentabilidade, pesquisadores como John (2000), Levy (1997) e Pinto (1999) enfatizam que este setor possui grande potencial para realizar grandes avanços em relação à sustentabilidade já que, na esfera ambiental, a indústria chega a consumir até $75 \%$ de recursos naturais. O impacto na flora, fauna e paisagem, devido à extração de matérias-primas (John, 2000) e consumo de energia e água, também são grandes problemas do setor, em que, se estima que $42 \%$ da energia elétrica consumida no Brasil, se dá em edificações construídas (ELETROBRAS, 2008).

Ademais, o setor pode contribuir significativamente com ações na esfera social, já que possui alto impacto na empregabilidade da população, principalmente de baixa renda e escolaridade. Segundo pesquisas do IBGE (2008), dos 4,1 milhões dos trabalhadores por conta própria no total das Regiões Metropolitanas, 1,6 milhões estavam alocados no grupamento da construção civil. Além disso, o setor impacta diretamente em um dos componentes do Índice de Desenvolvimento Humano (IDH ${ }^{i}$ ): a expectativa de vida ao nascer. Já que, segundo a UNC (2006), para cada percentual de aumento da construção na cobertura de esgoto sanitário, a expectativa de vida da população cresce em 0,18 ano.

Esta indústria também possui alta participação à perspectiva econômica da sustentabilidade, já que, segundo o relatório da UNC (2006), o desenvolvimento da infra-estrutura é essencial na determinação do nível de renda per capita de um país. Um levantamento realizado pela GV Consult (2004) apontou que o crescimento da construção em $10 \%$ da malha rodoviária por habitante em um país, eleva, em até $1,1 \%$, o nível de PIB per capita. Isso se dá, devido ao aumento de produtividade 
conseqüente da redução do tempo de deslocamento, bem como a integração de indústrias e trabalhadores de diversas localidades.

Por fim, a sustentabilidade é um conceito que vem evoluindo e tomando cada vez maiores proporções na indústria e em especial, no setor da construção civil. Segundo Dorsthorst e Hendriks (2000) soluções pontuais possuem menor efetividade, mas sim é necessário buscar soluções para fechar o ciclo produtivo, de tal forma a minimizar a saída de resíduos e a entrada de matéria-prima não renovável.

\subsection{Modelos de Estratégias de Posicionamento}

Michael Porter, em 1980, desenvolveu o Modelo das Cinco Forças, que tem como objetivo a análise do grau de atratividade de uma indústria no longo prazo, a partir de cinco fatores: o grau de rivalidade entre os concorrentes atuais, o poder de negociação dos fornecedores, o poder de negociação dos clientes, a ameaça de produtos substitutos e a possibilidade do surgimento de novos concorrentes (Farias Filho, 2009). As empresas devem posicionar-se de forma a ajustar suas capacidades à situação da indústria, a qual é caracterizada pelo peso relativo das cinco variáveis descritas, a fim de atingir seus objetivos estratégicos (Porter, 1980).

Neste contexto, Porter apresenta práticas "verdes" como um diferencial competitivo, pois investimentos nestas práticas proporcionam economia de recursos, eliminação de desperdícios e aumento da produtividade.

Partindo deste modelo e analisando as práticas da gestão sustentável existente tanto na literatura quanto em empresas, Srivastava (2003) propõe o Modelo das três forças para gestão da cadeia de suprimentos sustentável. As três forças identificadas como potenciais motivadoras são a economia, a legislação e o consumidor. Este tema vem ganhando popularidade entre a sociedade, o governo e a indústria, porém de forma distinta nos diferentes continentes. Na Europa, a força de maior peso é a regulatória; nos Estados Unidos, a econômica. Já os países em desenvolvimento encontram-se ainda em um estágio incipiente, onde tanto a globalização quanto a consciência do consumidor ainda dão os primeiros passos nesta direção (Srivastava, 2003).

\subsection{O Modelo das Quatro Forças}

A partir dos modelos descritos a cima, o Modelo das Quatro Forças (Gandhi, 2006) propõe três forças externas - regulatória, comunidade e consumidor - e uma interna - benefícios financeiros - que, juntas, seriam capazes de transformar o atual desenvolvimento insustentável de uma organização em desenvolvimento sustentável (DS). A abordagem consiste em partir de uma situação futura desejada e definir, de trás para frente, os resultados esperados. Ou seja, é um processo de determinar as etapas ou atividades que precisam ser realizadas para o atingimento da situação futura desejada.

As quatro forças motrizes, segundo o modelo, para a transformação "verde" de uma organização encontram-se na Figura 2. 


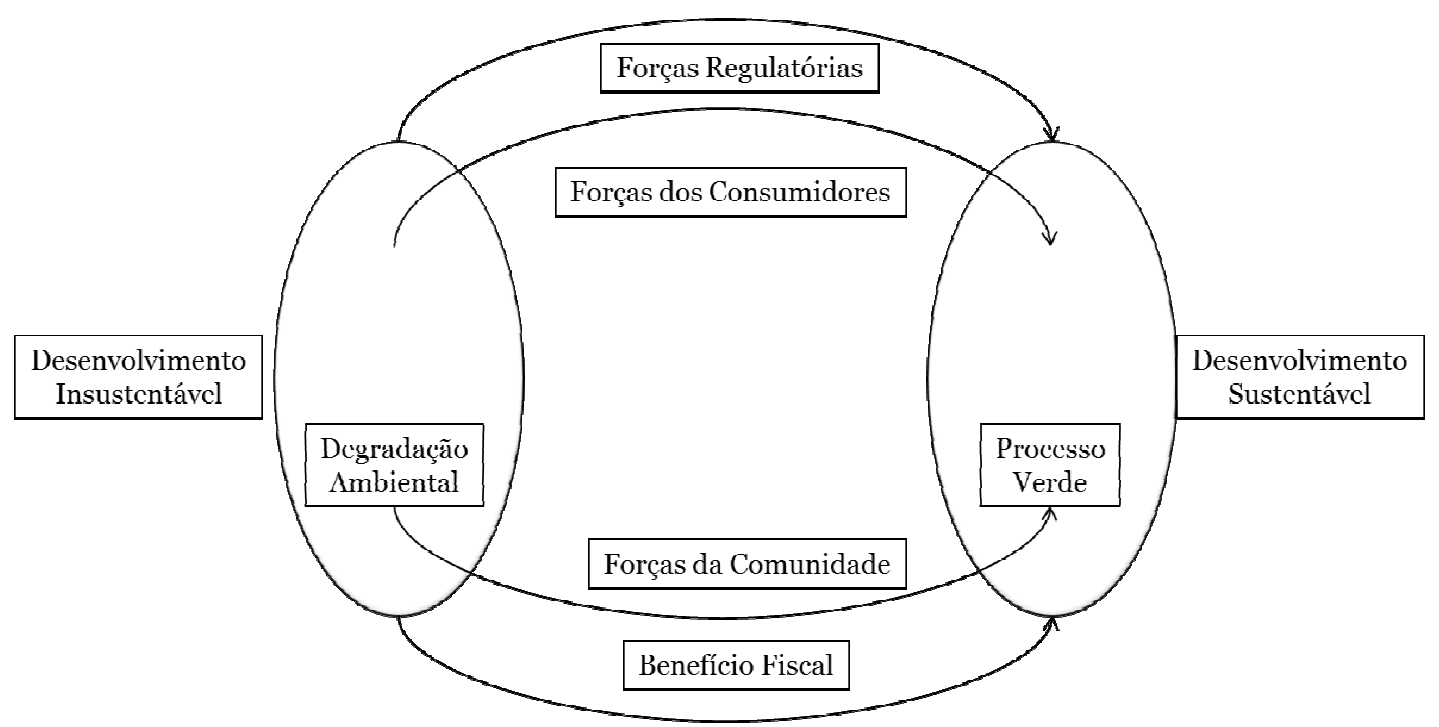

Figura 2 - Modelo das Quatro Forças (Gandhi, 2006)

A força regulatória consiste nas determinações legais impostas pelos governos no que tange o meio-ambiente. As empresas são forçadas a atender à legislação para a continuidade do seu negócio e, por isso, investem em Pesquisa e Desenvolvimento (P\&D) na busca de novos processos e/ou produtos que se adéqüem. Essa força pode ser também usada como barreira alfandegária, uma vez que os diversos países encontram-se em estágios de sustentabilidade bem distintos devido a suas próprias leis locais.

A força da comunidade é a que representa a sensibilidade da sociedade perante este tema, assim como aconteceu previamente em relação ao custo e, em seguida, à qualidade. Comunidades locais têm um papel fundamental na pressão imposta às empresas, visto que podem direcionar queixas ou reivindicações a órgãos específicos do governo (Gandhi, 2006).

De acordo com a Curva de Kuznet, a degradação ambiental é maior em estágios iniciais de crescimento econômico quando comparada com economias mais estáveis e desenvolvidas (Hayward, 2005). Comunidades mais ricas, com mais acesso à informação e à educação, irão buscar seu bem estar e uma vida mais segura, saudável e dentro da conformidade com o que acreditam ser o bem comum. Como o índice de pobreza vem baixando consideravelmente em países populosos, um maior número de pessoas passa a exercer essa pressão. O Instituto de Pesquisa Econômica Aplicada (Ipea), por exemplo, acredita que o Brasil poderá eliminar, nos próximos dez anos, os problemas de pobreza absoluta e extrema. De acordo com estudo realizado, em termos percentuais, a taxa de pobreza absoluta passou de $43,4 \%$ para $28,8 \%$ da população entre 1995 e 2008, enquanto a pobreza extrema caiu de $20,9 \%$ para $10,5 \%$ (Rosa, 2010).

A globalização estabeleceu novos formatos nas relações interpessoais, entre organizações e entre nações. Com a queda de barreiras e livre acesso a informações e tecnologias disponíveis globalmente, o consumidor adquiriu mais poder, assumindo a posição chave nos mercados, posição esta ora ocupada pelos vendedores. Ocorre, então, a transição da estratégia "Empurra" (empurrar o fluxo de produtos), na qual o produtor define sua produção a partir de suas necessidades, para a estratégia "Puxa" (puxar o fluxo de produtos), na qual os clientes ditam o que 
deve ser produzido, como e quando. Neste cenário, os consumidores, que representam uma das forças propostas pelo modelo, vêm demandando produtos e serviços com menos impactos ambientais e sociais e as empresas se vêem pressionadas a atender a esta nova demanda.

Segundo Gandhi (2006), a força interna do benefício financeiro ou econômico é a força de menor impacto sobre a transformação "verde" de uma empresa. Porém, Srivastava (2003) relata como a pressão de clientes internacionais influencia empresas indianas a implementar padrões ambientais e tomar iniciativas sustentáveis. Ou seja, aspectos econômicos e tecnológicos vêm também exercendo sua influência. Empresas irão investir em gestão e processos "verdes", uma vez que isto Ihe trará uma vantagem competitiva sustentável no longo prazo.

\section{METODOLOGIA}

\subsection{Enquadramento Metodológico}

Para elaboração da ferramenta proposta, foi adotada uma pesquisa exploratória, bibliográfica, qualitativa e com aplicação dos conceitos em um caso prático (Fleury, 2009). Isto é, em relação aos seus objetivos, trata-se de uma pesquisa exploratória, cuja aplicação tem por finalidade conhecer a variável de estudo tal como se apresenta, seu significado e o contexto onde ela se insere. Do ponto de vista de seu objeto, trata-se de uma pesquisa bibliográfica, na medida em que envolve leitura, análise e interpretação de livros, publicações e artigos acadêmicos. No que diz respeito à sua forma de abordagem, é uma pesquisa qualitativa, pois o desenvolvimento do modelo de gestão possui um caráter descritivo, as informações obtidas não são quantificáveis e tem um enfoque indutivo. Por fim, quanto à sua finalidade, é uma pesquisa aplicada, na medida em que objetiva gerar conhecimento para o esclarecimento de um problema específico, ou seja, foi fundamentada na necessidade de se identificar uma solução para uma questão prática. Isso posto, segue a seguir o encadeamento e o detalhamento das etapas da metodologia de pesquisa:

\section{$1^{a}$ etapa: Pesquisa bibliográfica}

A busca por referencial teórico foi realizada no Periódico CAPES, em livros, em associações e em revistas especializadas no assunto. Em paralelo, foram aprofundados os conhecimentos acerca dos modelos utilizados como base para 0 desenvolvimento da metodologia proposta neste artigo: a ferramenta de análise de maturidade de Gabriele et al. (2009) e o Modelo de Quatro Forças de Gandhi (2006). Esta etapa foi de grande relevância para o entendimento dos problemas inerentes ao tema e os principais pontos a serem desenvolvidos neste estudo.

\section{$2^{\mathrm{a}}$ etapa: Análise integrada dos modelos base}

Após o entendimento dos modelos base e revista a literatura, foi realizada uma análise integrada de como os modelos poderiam corroborar para o desenvolvimento de uma ferramenta que proporcione o levantamento e a priorização 
das ações que a empresa deve investir para alavancar o seu ambiente atual para um ambiente sustentável.

\section{$3^{a}$ etapa: Elaboração da ferramenta proposta}

Nesta etapa foi desenvolvida a métrica de avaliação da ferramenta, ou seja, a forma e os parâmetros que o método utiliza para buscar e ranquear as ações de melhoria que a empresa deve implementar em nível tático e operacional para promover um ambiente sustentável.

\section{$4^{a}$ etapa: Aplicação da ferramenta}

Para validar a aplicabilidade da ferramenta proposta, foi desenvolvido um estudo de caso em uma empresa do setor de construção civil, especificamente em uma Central Dosadora de Concreto.

\section{RESULTADO}

A metodologia proposta neste artigo utiliza como base a saída dos dados da ferramenta de análise do nível de maturidade da empresa em relação à sustentabilidade, desenvolvido por Gabriele et al. (2009). Em seguida, estes dados são trabalhados de forma integrada ao Modelo de Quatro Forças de Gandhi (2006) e demais informações levantadas no capítulo de revisão da literatura. Por isso, este capítulo tem como objetivo explanar acerca do modelo de maturidade previamente desenvolvido, para em seguida, apresentar a ferramenta elaborada no presente estudo.

\subsection{Ferramenta de análise de maturidade da empresa em relação à sustentabilidade}

Embora existam inúmeros instrumentos em nível internacional para a medição da sustentabilidade, este modelo foi escolhido por ser de utilização fácil, simples e prática. Ademais, a ferramenta é voltada para pequenas e médias empresas do setor da construção civil, que acabam por dispor de poucos recursos para investir nestes instrumentos de avaliação.

O modelo constitui de uma matriz que agrupa indicadores do Global Reporting Initiative (GRI") e do Índice de Sustentabilidade Empresarial da Bovespa (ISE ${ }^{\text {iii) }}$ segundo três dimensões de avaliação. A primeira perspectiva compreende os pilares da sustentabilidade (TBL): econômico, ambiental e social. Já a segunda dimensão possui um enfoque estratégico, correspondendo às perspectivas do Balanced Scorecard $\left(\right.$ BSC $\left.^{\text {iv }}\right)$, ou seja, utilizando os parâmetros: financeiro, clientes, processos internos e aprendizagem e conhecimento. Por fim, a última dimensão procurou enfatizar a visão organizacional, por meio dos critérios utilizados no ISE, ou seja: política e planejamento, gestão, desempenho e cumprimento legal. As dimensões da matriz resultante podem ser observadas na Figura 3. 


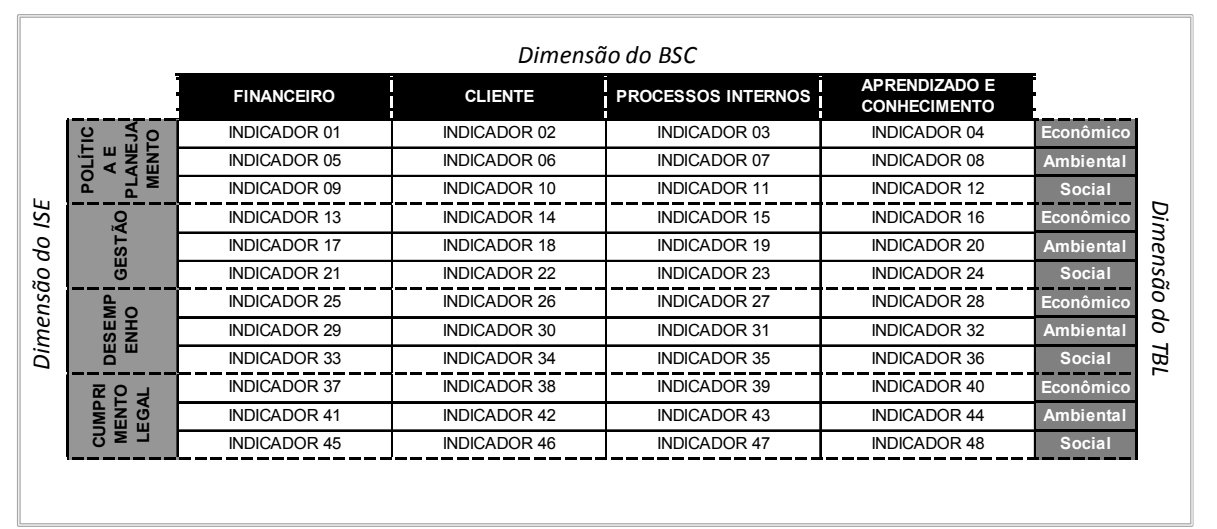

Figura 3 - Matriz de avaliação da sustentabilidade (adaptado: Gabriele et al., 2009)

Conforme ilustrado na Figura 3, para cada quadrante da matriz, foram agrupados os indicadores do GRI e do ISE, que serviram como base para a elaboração de um questionário quantitativo.

Com a finalidade de obter uma métrica de avaliação do modelo elaborado, foi solicitado a três especialistas das áreas de sustentabilidade, estratégia e construção civil a atribuírem ponderações aos indicadores propostos, segundo o método Analytic Hierarchy Process (AHP). Por conseguinte, no momento em que o gestor responde o questionário, um valor é atribuído à questão e este é multiplicado pelo seu peso relativo. No final, a soma dos valores das questões respondidas poderá variar de 0 a 400 pontos, de forma que a empresa se enquadra em faixas de pontuação. Para cada faixa de pontuação foi definido um nível de maturidade defensiva, reativa, proativa, voluntária e sustentável - que foram descritos conforme a revisão da literatura realizada pelos autores. Entretanto, convém ressaltar que a metodologia foi desenvolvida de forma que quanto maior o nível de maturidade que a empresa se enquadra, maior é a dificuldade de implementação de ações para que a organização alcance o nível seguinte.

Por fim, esta ferramenta permite que, por meio da introdução dos dados da empresa, obtenha-se um retorno simples e generalista sobre o nível de maturidade da organização em relação à sustentabilidade. Além disso, será obtido o grau de aderência da empresa às perspectivas organizacionais, de sustentabilidade e de estratégia em conjunto e separadamente.

\subsection{Método proposto: Metodologia SUSTENTAR}

A ferramenta de análise de maturidade da empresa em relação à sustentabilidade tem como saída o nível de sustentabilidade que a empresa se enquadra. Além disso, proporciona percentuais de adesão da empresa para cada perspectiva da matriz proposta na ferramenta, ou seja, para os três pilares da sustentabilidade (econômico, social e ambiental), os quatro critérios estratégicos do Balanced Scorecard (financeiro, clientes, processos internos e aprendizagem e conhecimento) e para a capilarização organizacional, conforme os quatro critérios do Índice de Sustentabilidade Empresarial da Bovespa (política e planejamento, gestão, desempenho e cumprimento legal). 
Com base nesses resultados, a empresa deve realizar um levantamento ou Brainstorming junto aos seus líderes, colaboradores, fornecedores, clientes, concorrentes, parceiros, dentre outras partes interessadas. O objetivo desta etapa é mapear as possíveis ações que podem promover melhorias em relação aos pontos a desenvolver destacados pela ferramenta.

Em seguida, para cada ação de melhoria mapeada, a equipe deve analisar se existe ou não impacto direto sob cada uma das perspectivas da ferramenta de análise da maturidade em relação à sustentabilidade. Caso exista impacto, será atribuído à ação um peso inverso ao grau de aderência diagnosticado na ferramenta. Com isso, para cada ação levantada, serão somados os pesos atribuídos a todas as perspectivas da ferramenta de maturidade, em que o somatório poderá variar de 0 a 11 pontos por ação. O objetivo é que as ações que impactam em critérios com maior deficiência obtenham uma pontuação mais elevada que as demais.

Em paralelo, a equipe deve analisar cada ação de melhoria levantada, conforme sua influência em relação às forças do Modelo de Quatro Forças (regulatória, comunidade, consumidor e benefícios financeiros). Para cada força percebida, devem ser somados 2,75 pontos na pontuação deste bloco de análise. No final, o somatório dos pesos por ação deve variar de 0 a 11 pontos, assim como a ponderação da perspectiva anterior.

Por fim, para cada ação levantada, será realizada a análise integrada e igualitária dos pontos a desenvolver da empresa quanto ao seu nível de maturidade em relação à sustentabilidade e suas pressões percebidas pelo Modelo de Quatro Forças. Esse nexo será realizado por meio do somatório das duas pontuações resultantes, em que as ações que obtiverem uma maior pontuação final, deverão ser priorizadas no plano de ação da empresa. A Figura 4 apresenta o fluxograma deste processo. 


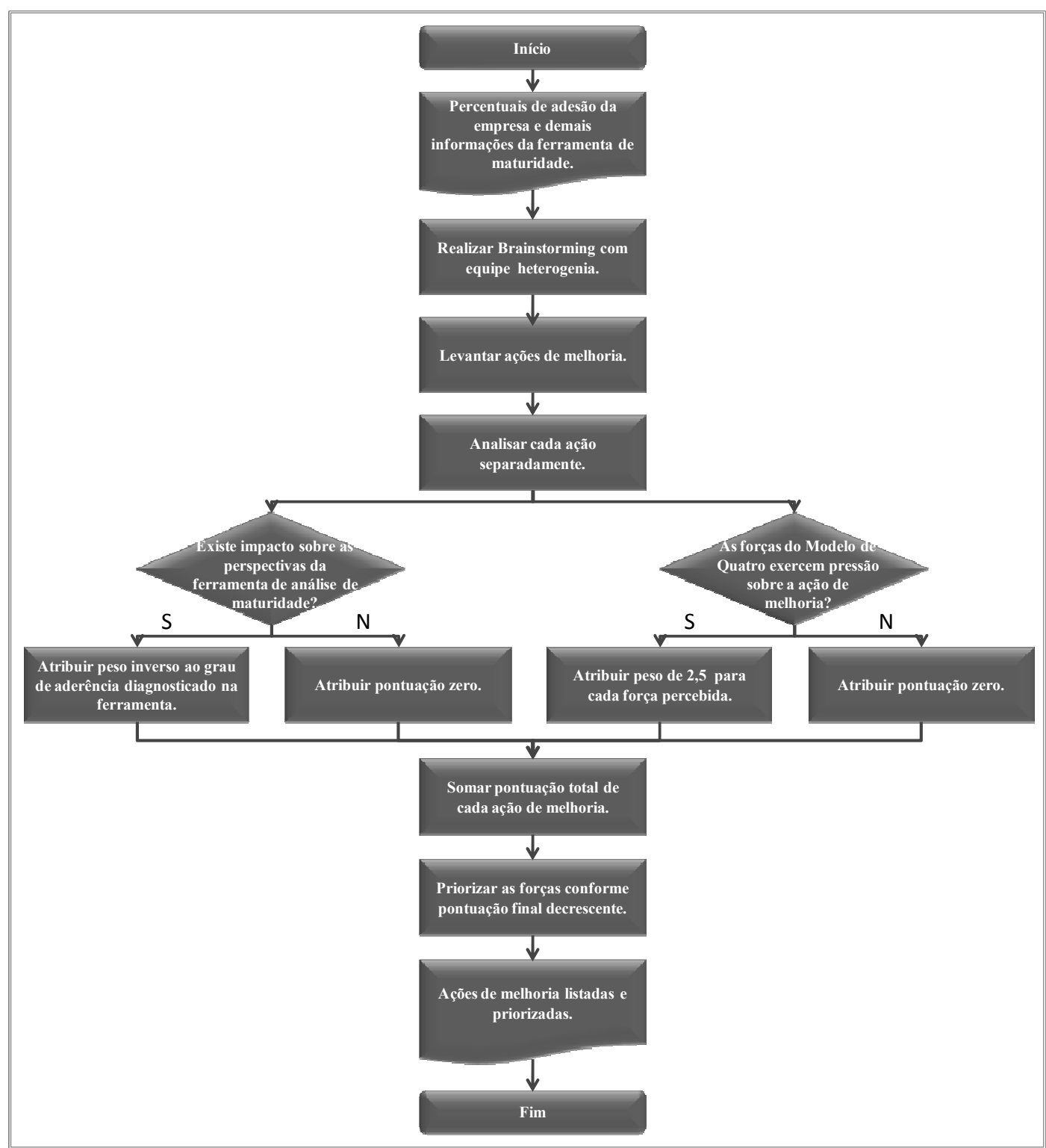

Figura 4 - Fluxograma da metodologia do Metodologia SUSTENTAR (Os autores, 2010)

Conforme apresentado na Figura 4, no final deste processo, a empresa terá uma lista de ações de melhorias priorizadas para transformação de seu atual ambiente em um ambiente sustentável.

\section{ESTUDO DE CASO}

$\mathrm{Na}$ estruturação do presente capítulo, foram levantadas pesquisas bibliográficas sobre as especificidades do setor de Centrais Dosadoras de Concreto (CDC). Concomitantemente, foi realizada uma pesquisa de campo em uma CDC, na qual houve a participação de funcionários de nível operacional, engenheiros responsáveis pelo gerenciamento da produção e de um diretor da empresa. 


\subsection{Contextualização do Setor}

O concreto é uma espécie de rocha artificial produzida por meio da mistura de cimento, água e agregados, tais qual areia, cascalho de rio, pedra, cascalho britado, dentre outros materiais. Além disso, podem ser realizadas adições e incluídos aditivos que alteram as características físicas e químicas do produto. A proporção dos materiais contemplados na mistura, denominada "traço", é o que determina o tipo de resistência e endurecimento ideal do concreto para um respectivo tipo de construção (SEAE, 2006). Por isso, os sistemas produtivos das CDC tendem a ter características operacionais de produção puxada.

Historicamente, 0 segmento concreteiro tem se mostrado bastante especializado, modernizando-se constantemente na busca de equipamentos e sistemas automatizados que permitam dosagens em central (ABESC, 2010). Essa automatização corrobora para o aumento dos níveis da qualidade dos produtos exigidos pelos clientes, além de minimizar os impactos ambientais ao longo da produção. Outrossim, a automatização da indústria influencia diretamente o pilar social, devido à redução da necessidade de mão de obra operária no processo.

Em relação ao ambiente da indústria, o mercado nacional de produção e distribuição de concreto é caracterizado pela verticalização do setor, resultado de fusões e aquisições de empresas de cimento e serviços de concretagem (SEAE, 2006). Tal movimento enfatiza a concorrência entre as empresas, dificultando, cada vez mais, a entrada de organizações de pequeno porte neste segmento. Além disso, segundo o presidente do Sindicato Nacional das Empresas de Serviços de Concretagem, em entrevista divulgada pela revista SIM (Gouveia, 2010), o setor possui denúncias de sonegação, evasão e elisão fiscal da ordem de $R \$ 300.000 .000$, provocando danos ao erário e, conseqüentemente, à sociedade.

Ao analisar esta indústria sob o enfoque dos parâmetros dos preços, foi constatada uma anomalia do mercado brasileiro quando comparado aos valores praticados no mercado internacional (Papa, 2003). Em linhas gerais, este efeito ocorre devido aos custos elevados de impostos e ao o aumento da demanda por areia no mercado nacional e exaustão das reservas de agregados (Valverde, 2001). Além disso, segundo a norma NBR 7112, o concreto sem aditivos deve ser utilizado em até duas horas após sua preparação, pois após esse período, o processo de endurecimento é iniciado. Por isso, as dificuldades logísticas no Brasil, tais como o trânsito, que impacta diretamente no tempo em que o produto permanece em circulação, têm contribuído para perdas no setor. Ademais, o pedagiamento, os limites de peso transportados por eixo e o aumento das distâncias de carga (Papa, 2003) são variáveis que influenciam diretamente nos preços praticados pelo setor.

Sob a perspectiva ambiental, segundo a ABESC (2010), um estudo coordenado pelo Departamento de Engenharia Civil da Escola Politécnica da Universidade de São Paulo identificou que 9\% da produção brasileira de concreto ocorrem sob a forma de perdas. Já na Europa, o desperdício varia de $1 \%$ a $4 \%$ em relação ao volume total dosado. Além disso, um aspecto ambiental em voga é referente à emissão de gases que contribuem para o aumento do efeito estufa. Segundo Tarun (2008), a produção de uma tonelada de cimento portland, componente principal do concreto, produz cerca de uma tonelada de $\mathrm{CO} 2$, dentre outros gases. No Brasil a produção de cimento e concreto corresponde de $6 \%$ a $8 \%$ da emissão CO2 emitido na atmosfera (CDIAC, 2000). 
Por fim, com a finalidade de padronizar e minimizar muitos desses efeitos negativos da produção destacados ao longo deste capítulo, no Brasil, as CDC são reguladas por normas técnicas da Associação Brasileira de Normas Técnicas (ABNT, 2010a), das quais se destacam as: NBR 11709, NBR 7484, NBR 11953, NBR 12822, NBR 8361, NBR 8936, MB 1311 NBR 8953 e NBR 6118. Esta última, segundo a ABNT (2010b), tornou-se referência internacional devido ao seu reconhecimento oficializado pela International Organization for Standardization (ISO). Além disso, assim como as demais indústrias, as CDC devem possuir licenças ambientais (prévias, de instalação e de operação) para manter sua produção legalizada.

\subsection{Caracterização da Empresa}

A organização na qual foi realizado o estudo possui atuação nacional desde a década de setenta, com cem unidades distribuídas pelo país e com mais de setecentos equipamentos. É composta por cerca de duzentos colaboradores e possui capacidade de produção de dois milhões de metros cúbicos de concreto por ano.

A unidade visitada possui capacidade de produção de quarenta metros cúbicos por hora e emprega 12 funcionários, dos quais nenhum participa do programa jovem aprendiz ou é portador de deficiência. Sua localização física se encontra em zona de uso estritamente industrial, situada no Rio de Janeiro, especificamente na Bacia Aérea $n^{\circ} 1$, Região Hidrográfica IV, conforme classificação do Instituto Estadual do Ambiente (INEA, 2010).

Suas instalações possuem todas as licenças ambientais de instalação e operação e comportam. Ademais, não existe uma área na unidade voltada para pesquisa e desenvolvimento de novos materiais e o gestor da unidade desconhecia a existência de um grupo de pesquisa na sede.

A captação e utilização da água possuem processo autorizado pela SERLA e o Sistema de Tratamento de Esgoto está de acordo com a NBR 13969/97 e a DZ 215 R4 da FEEMA. Além disso, não há fonte de poluição do solo e os ruídos gerados no processo se restringem ao local da operação, não ocasionando poluição sonora para a sociedade do entorno.

A gestão de resíduos sólidos segue as normas de recolhimento do CONAMA 307, específico para materiais de construção civil. Por isso, essas perdas são tratadas como custos do processo produtivo, em que não há reciclagem de material ou aproveitamento dos resíduos para fins lucrativos.

Além disso, dentre os principais mecanismos de controle de poluição diagnosticados, destacam-se: os filtros manga instalados nos silos de cimento; o fechamento lateral da balança de agregados; a cobertura das correias transportadoras; caixa separadora de água e óleo e caixa de decantação para não poluição de rios; e a umidificação dos agregados em estoque por meio de aspersores, evitando dispersão de partículas durante a movimentação dos materiais.

O sistema de qualidade engloba testes de amostragem desde o recebimento da matéria-prima até o produto final. Existe um sistema de monitoramento dos produtos, permitindo o controle da qualidade dos bens produzidos e proporcionando rápidos retornos às demandas por informação dos estágios do processo produtivo pelos clientes. De forma complementar, em caso de incorporação de novas 
tecnologias, a gerência desenvolve programas de treinamento pontuais aos funcionários, bem como aos clientes.

A unidade estudada possui automação em nível da produção, incluindo a utilização de um sistema MRP, com a finalidade de controlar as quantidades de material utilizadas e necessárias no processo produtivo. O sistema de gestão da qualidade possui integração junto a este sistema, formando um banco de dados único para análise do gestor da produção.

Não foi possível ter acesso aos dados quantitativos financeiros precisos das operações da organização, porém segundo entrevista junto ao diretor, a organização possui projeções de fluxos de caixa positivos, com alto retorno do investimento em relação ao mercado. Segundo este mesmo representante da empresa, a unidade visitada cumpre com todas as suas obrigações tributárias, encontra-se em situação regular junto à Receita Federal e nunca recebeu uma multa ou sanção administrativa.

\subsection{Aplicação da Ferramenta Proposta para Identificação do Nível de Maturidade em Relação à Sustentabilidade}

Durante a visita técnica realizada, os funcionários da Central Dosadora de Concreto responderam ao questionário de avaliação da sustentabilidade proposto, a partir do qual foi possível mensurar o nível de maturidade sustentável que caracteriza a empresa.

Da possível pontuação de 0 a 400 pontos, a empresa obteve um total de 193,2 pontos, sendo enquadrada no terceiro dos cinco níveis possíveis de maturidade em relação à sustentabilidade, de acordo com a ferramenta utilizada. Esse nível de maturidade é caracterizado em linhas gerais como:

"A organização possui algum enfoque sustentável para a tomada de decisão, bem como para as suas ações, de forma que a corporação age antes de a ameaça existir, a fim de evitar que ela surja. Existe o uso continuado nas principais práticas da organização, com controles atuantes. Há a possibilidade de fomento de inovações, bem como ocorrem alguns refinamentos de suas ações decorrentes do aprendizado. As práticas de gestão são coerentes com a estratégia da organização, mas existem algumas lacunas entre os resultados esperados e obtidos." (Gabriele et al., 2009)

Ademais, foram gerados os percentuais e gráficos-radares que representam o nível de aderência da empresa às perspectivas dos pilares da sustentabilidade, estratégia e visão organizacional, quando analisados em conjunto. A Figura 5 apresenta os resultados encontrados. 


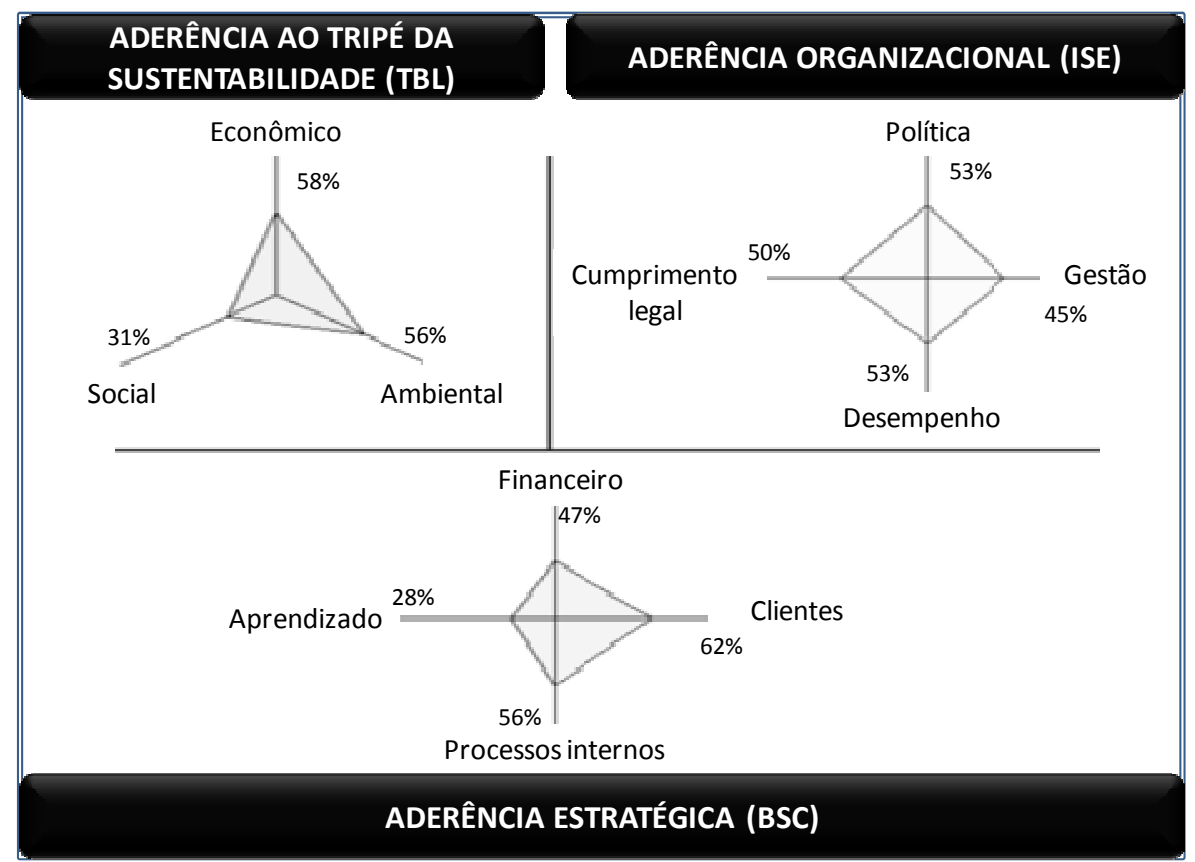

Figura 5 - Gráficos-radares resultantes da avaliação de cada dimensão da matriz (Os autores, 2010)

Conforme os resultados apresentados na Figura 5 e as demais informações levantadas na pesquisa de campo, pretende-se realizar no capítulo seguinte uma análise acerca dos resultados obtidos.

\section{DISCUSSÃO E ANÁLISE DE RESULTADOS}

\section{1. Análises da Maturidade da Sustentabilidade em uma Empresa do Setor de Construção Civil}

A partir da aplicação do modelo de análise de maturidade proposto por Gabriele et al. (2009), obteve-se os gráficos ilustrados na Figura 5 e o enquadramento da empresa no terceiro dentre os cinco níveis existentes no modelo em relação à sustentabilidade. Ao longo deste capítulo, pretende-se realizar uma análise crítica de cada uma das dimensões de avaliação abordadas na ferramenta, em relação ao contexto das empresas que compõem a cadeia produtiva da construção civil, conforme estudo realizado no capítulo de revisão da literatura.

Em relação à dimensão do Tripé da Sustentabilidade (TPL), o gráfico aponta que a empresa possui um percentual bom de adesão às questões econômicas $(58 \%)$ e ambientais $(56 \%)$ nas decisões e ações corporativas. Devido à proximidade constatada no grau de importância conferida às questões ambientais em relação aos fatores econômicos, verifica-se que a organização obteve um destaque significativo perante as empresas atuantes no seu setor, porém não ótimo. Já sob a ótica social (31\%), percebeu-se que a empresa segue o padrão do setor da construção civil, ou seja, dispõe de baixo direcionamento de recursos a este fator, resultando em um desempenho reduzido segundo seu potencial de atuação. 
Segundo a perspectiva dos pilares estratégicos e a revisão da literatura, a empresa demonstra possuir uma atuação arrojada segundo o foco de priorização das ações corporativas, conferindo $62 \%$ da importância de suas ações aos Clientes. Outrossim, é constada uma maior preocupação com o nível dos Processos Internos $(56 \%)$, devido à alta exigência de qualidade e customização inerente ao seu produto. A importância aplicada ao fator Financeiro foi de $47 \%$, enquanto às ações de Aprendizado e Conhecimento foi de $28 \%$. Este último é destacado como um ponto que deve ser mais bem desenvolvido na empresa, com a finalidade de reduzir as perdas e diagnosticar novas oportunidades de negócio por meio da gestão da produção, além de estreitar as relações com as partes interessadas.

Já em relação à terceira dimensão de avaliação, os critérios do ISE, a empresa apresentou uma alta capilarização de seu planejamento. Embora não possua um percentual de adesão ótimo, em torno de $50 \%$, as decisões corporativas permeiam os níveis estratégico, tático e operacional da organização, conferindo um destaque à empresa em relação ao setor estudado.

Portanto, após a análise de cada uma das dimensões de avaliação, conclui-se que a empresa retrata uma boa atuação quando comparada ao setor em que está inserida. Entretanto, a ferramenta diagnosticou alguns aspectos nos quais deve ser agregada maior importância, com fins de garantir sua perpetuidade no mercado. Além disso, convém mencionar que o direcionamento dos recursos para que a organização mude de nível de maturidade em relação à sustentabilidade deve ser bem estruturado, visto que, quanto maior o seu nível, maior a dificuldade da empresa atingir o nível seguinte.

\subsection{Aplicação do Método Proposto: Metodologia SUSTENTAR}

\subsubsection{Brainstorming e Levantamento das Açoes de Melhoria}

A partir da análise da maturidade da Central Dosadora de Concreto (CDC) em relação à sustentabilidade, foi levantado um conjunto de ações factíveis que podem contribuir para o aumento do grau de maturidade da empresa por meio das forças do Modelo de Quatro Forças.

Conforme observado no capítulo anterior, por a empresa não optar por reciclagem de concreto, incentivos em pesquisa e desenvolvimento e relações mais estreitas com a comunidade do entorno, existem diversas ações sob as quais a organização poderia alavancar sua sustentabilidade. Essas ações promoveriam benefícios financeiros por meio de novos negócios e parcerias com o governo e entidades privadas, além de benefícios ambientais, sociais e econômicos para a sociedade e o consumidor.

Em relação à reciclagem do concreto, pontua-se que o reaproveitamento de resíduos passa a ganhar maior destaque em relação ao cumprimento legal da empresa, devido à aprovação da nova lei da Política Nacional de Resíduos Sólidos (Adeodato, 2010). No caso da CDC analisada, esse reaproveitamento poderia ser realizado por meio da implementação de um projeto piloto de gestão ambiental de resíduos que, segundo Pinto (1999), pode promover cerca de $40 \%$ de redução nos custos e percepção de mudança positiva da imagem da empresa em até $87 \%$. Outra alternativa, seria o envio dos resíduos de concreto às usinas de reciclagem (Paulera, 2010), pela instalação de sistemas internos de reciclagem. Esses sistemas permitem 
a separação da água e do concreto de forma que ambos os resíduos da operação possam ser reaproveitados. Após a separação, o concreto deve ser moído e transformado em pedriscos que, ao adicionar cimento, podem ser utilizados para a fabricação de: tubos para rede de água, placas para calçada, blocos para pavimentação, blocos de alvenaria, meio-fios, bancos de praça, dentre outras utilidades para obras públicas e privadas (Fioriti, Ino, Akasaki, 2007).

Além disso, os resíduos de concreto podem ser misturados com resíduos de borracha, como por exemplo, pneus descartados, para o desenvolvimento de blocos de concreto para pavimentação intertravada. Segundo Fioriti, Ino e Akasaki (2007), este material poder ser utilizado apenas em pavimentações com leve solicitação, pois a mistura promove a redução da resistência à compressão e o aumento à capacidade de absorção de energia, ou seja, à tenacidade do concreto.

Ademais, segundo Ulsen (2010) um dos principais problemas para o reaproveitamento do concreto é a sua falta de viabilidade para fins estruturais, tais qual a construção de colunas de edifício, devido a sua fragilidade e não atendimento aos padrões da ABNT. Por esses dentre outros motivos, os incentivos em pesquisa e desenvolvimento pela empresa, sejam internos ou em parcerias com universidades, podem fornecer vantagens competitivas de qualidade do material, preços atrativos e desenvolvimento de novos produtos frente aos seus concorrentes.

Por fim, o estreitamento das relações com a sociedade do entorno promoveriam maior adesão às práticas de sustentabilidade, de forma a alavancar a deficiência da empresa no pilar social, além de manter boas relações com as regiões ribeirinhas.

\subsubsection{Contribuições para Alavancagem da Sustentabilidade da Empresa Analisada}

Com base nos percentuais resultantes da ferramenta de análise da maturidade da empresa em relação à sustentabilidade, foram obtidas as seguintes pontuações por critérios da matriz:

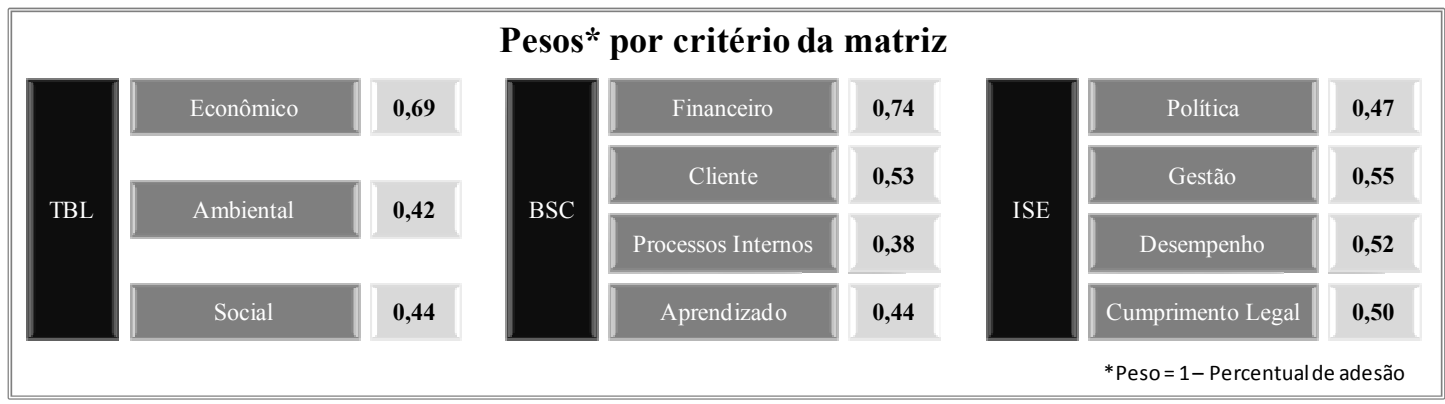

Figura 6 - Pontuação por critério de avaliação (Os autores, 2010)

Para cada ação mapeada, foi verificada a existência de impacto direto sobre cada critério pontuado na Figura 6. Para os casos positivos, foram atribuídas e somadas as respectivas pontuações. No caso desta Central Dosadora de Concreto (CDC), a pontuação máxima por ação neste bloco de avaliação é de 5,68 pontos. 
Concomitantemente, cada ação foi avaliada em relação às pressões sofridas por cada força do Modelo de Quatro Forças (regulatória, comunidade, consumidor e benefícios financeiros), conferindo 2,5 pontos por força. Com isso, a pontuação máxima de cada ação neste bloco de análise será de 11 pontos.

Em seguida, foi realizada a análise integrada do nível de maturidade da CDC em relação à sustentabilidade e às pressões exercidas pelo Modelo de Quatro Forças, por meio do somatório das pontuações resultantes. No final, as ações propostas foram priorizadas conforme maior fosse sua pontuação final, conforme apresentado na Tabela 1.

Tabela 1 - Priorização do plano de melhorias (Os autores, 2010)

\begin{tabular}{|c|c|c|c|c|c|c|}
\hline \multirow[b]{2}{*}{ Priorização } & \multirow[b]{2}{*}{ Ações de melhoria } & \multirow[b]{2}{*}{$\begin{array}{c}\text { Modelo de } \\
\text { Quatro Forças }\end{array}$} & \multicolumn{3}{|c|}{ Ferramenta de Análise da Maturidade } & \multirow[b]{2}{*}{$\begin{array}{c}\text { Resultado } \\
\text { Final }\end{array}$} \\
\hline & & & TBL & BSC & ISE & \\
\hline 10 & Implementar um projeto piloto de gestão ambiental de resíduos. & 10 & 0,86 & 1,35 & 1,57 & 13,78 \\
\hline 20 & $\begin{array}{l}\text { Desenvolver uma área de pesquisa e/ou realizar parcerias com universidades com a } \\
\text { finalidade de promover materiais menos agressivos ao meio-ambiente e/ou com melhor } \\
\text { preço e qualidade. }\end{array}$ & 7,5 & 1,55 & 2,09 & 0,52 & 11,66 \\
\hline 3⿻ & Obter maior proximidade à sede para pesquisa e desenvolvimento. & 7,5 & 1,11 & 1,71 & 1,07 & 11,39 \\
\hline 49 & Enviar os resíduos da produção para reciclagem em usina. & 5 & 1,55 & 0,53 & 1,05 & 8,13 \\
\hline 5o & Instalar sistemas internos de reciclagem. & 5 & 0,88 & 1,71 & 0,5 & 8,09 \\
\hline 6o & $\begin{array}{l}\text { Desenvolver materiais para a venda com as sobras de concreto, tais quais: tubos para rede } \\
\text { de água, placas para calçada, blocos para pavimentação, blocos de alvenaria, meio-fios, } \\
\text { bancos de praça, dentre outros. }\end{array}$ & 5 & 1,55 & 0,97 & 0,5 & 8,02 \\
\hline 70 & Contratar portadores de deficiência. & 5 & 0,69 & 1,12 & 1,05 & 7,86 \\
\hline 80 & Contratar e desenvolver estagiários e jovens aprendizes da comunidade do entorno. & 2,5 & 1,11 & 1,12 & 1,02 & 5,75 \\
\hline 9요 & Desenvolver um processo de gestão da informação e gestão da mudança. & 2,5 & 0,42 & 1,27 & 1,07 & 5,26 \\
\hline 10 은 & Desenvolver um programa de treinamento e aprendizado. & 2,5 & 0,42 & 1,27 & 1,02 & 5,21 \\
\hline 110 & $\begin{array}{l}\text { Buscar parcerias com construtoras e/ou com o governo, para realização de pequenas obras } \\
\text { para a sociedade do entorno, em que poderia contribuir doando as sobras de concreto para } \\
\text { a construção. }\end{array}$ & 2,5 & 1,13 & 0,38 & 1,02 & 5,03 \\
\hline
\end{tabular}

Por fim, conforme apresentado na Tabela 1, as ações que recebem maior pressão das forças do Modelo de Quatro Forças, bem como impactam nos fatores menos desenvolvidos pela empresa, foram priorizadas pela empresa de forma a alavancar a sua maturidade em relação à sustentabilidade.

\section{CONCLUSÃO}

A utilização da ferramenta de análise da maturidade da sustentabilidade em conjunto com o Modelo de Quatro Forças possibilitou a realização de uma análise da situação atual da sustentabilidade da empresa e propor ações de melhoria direcionadas para a implantação um desenvolvimento sustentável. Apesar da análise da situação atual da empresa não ter demonstrado um nível baixo de maturidade da sustentabilidade, foram encontradas diversas oportunidades de melhorias, principalmente relacionadas ao aspecto social, que se mostrou o menos desenvolvido. Os aspectos econômicos e ambientais são os mais desenvolvidos em virtude da natureza do negócio, pois são feitas muitas exigências para a empresa poder operar.

Esta análise demonstrou que as empresas ainda estão em um nível inicial de desenvolvimento sustentável, agindo somente de acordo com legislações e normas, sem muito empenho no desenvolvimento de inovações tanto para a melhoria do meio ambiente, quanto para a continuidade de seu negócio de mercado, pois a sustentabilidade não trata apenas dos aspectos ambientais. Muito ainda deve ser 
desenvolvido para a conscientização dos gestores de que ações voltadas para a sustentabilidade podem gerar vantagem competitiva e não custos, como muitos pensam.

O desenvolvimento de ferramentas práticas de análise e implantação de ações voltadas para o desenvolvimento sustentável também é uma lacuna atual, no qual o Modelo de Quatro Forças e a ferramenta de análise da maturidade da sustentabilidade tentam se inserir, não de uma forma exaustiva, mas com o objetivo de identificação da situação atual e direcionar a análise de evolução da gestão empresarial no caminho do desenvolvimento sustentável.

\section{REFERÊNCIAS}

ABESC - Associação Brasileira das Empresas de Serviço de Concretagem, Utilização de finos no concreto estrutural, Brasil, 2010, Disponível em: <http://www.abesc.org.br/pdf/mambiente.pdf> , Acesso em: 03 mai 2010.

ABNT - Associação Brasileira de Normas Técnicas, Normas brasileiras, Brasil, 1997, Disponível em: http://www.abnt.org.br/imagens/imprensa/Editais_e_afins_Boletim/Bol_082009_Encarte_Bol etim_Normalizacao.pdf>, Acesso em: 20 jun 2010a.

ABNT - Associação Brasileira de Normas Técnicas, ABNT NBR 6118:2003 é reconhecida na ISO. Brasil, 1997, Disponível em: <http://www.abnt.org.br/m5.asp?cod_noticia=141\&cod_pagina=965>, Acesso em: 20 jun 2010b.

ADEODATO, S., A nova era da reciclagem, Planeta Sustentável, Brasil, 2010, Disponível em: < http://planetasustentavel.abril.com.br/noticia/lixo/nova-era-reciclagem-lixo-gestaoresiduos-politica-nacional-575374.shtml>, Acesso em: 02 jul 2010.

BRASIL, Nota Técnica Conjunta $n^{\circ} 07$ SEAE/MF -SDE/MJ, Problemas concorrenciais decorrentes da reforma da Norma NBR 12655, Ministério da Fazenda e Ministério da Justiça, Brasília, DF, 31 jan 2006.

BRITO, G., Gestão sustentável nas empresas, Notas de aula, Mestrado em engenharia de produção, Universidade Federal Fluminense, Niterói, RJ 1 mar 2010.

CDIAC - Carbon Dioxide Information Analysis Center, Carbon Cycle, Estados Unidos, 2010. Disponível em: < http://mercdev3.ornl.gov/cdiac/send/query>. Acesso em: 02 abr 2010.

COMISSÃO MUNDIAL SOBRE O MEIO AMBIENTE E O DESENVOLVIMENTO - CMMAD, Relatório Nosso Futuro Comum, 2a ed. Rio de Janeiro: Editorada Fundação Getulio Vargas, 1991. 430p.

COPEL - Companhia Paranaense de Energia, Relatório anual de gestão e sustentabilidade, Disponível em: <http://www.copel.com/relatoriosanuais/2008/pt/relatorio/01_03.htm>, Acesso em: 03 de abr 2010.

DORSTHORST, B, HENDRIKS, Ch. F. Re-use of construction and demolition waste in the EU. In: CIB Symposium: Construction and Environment - theory into practice. São Paulo: EPUSP, 2000. 
ELETROBRAS. PROCEL, 2008. Disponível em: <www.eletrobras.gov.br>. Acesso em: 07 de abr 2010.

FARIAS FILHO, J. R., Administração estratégica, Notas de aula, Mestrado em engenharia de produção, Universidade Federal Fluminense, Niterói, RJ 1 agos 2009.

FARIAS FILHO, J. R., OLIVEIRA, J. T., GABRIELE, P. D., Proposta de Ferreamenta de Avaliação Preliminar do Nível de Maturidade da Sustentabilidade Empresarial no Setor de Construção Civil, V Congresso Nacional de Excelência em Gestão, Rio de Janeiro: 2009.

FIORITI, C. F., INO, A., AKASAKI, J. L., Avaliação de blocos de concreto para pavimentação intertravada com adição de resíduos de borracha provenientes da recauchutagem de pneus, Associação Nacional de Tecnologia do Ambiente Construído, Brasil: 2007.

FLEURY, A.; MELLO, C. H. P.; NAKANO, D. N.; TURRINIONI, J. B.; HO L. L.; MORABITO, R.; MARTINS, R. A.; PUREZA, V. Metodologia de pesquisa em engenharia de produção e gestão de operações. São Paulo: Campus; 2010.

GANDHI, N.M; SELLADURAI, V e SANTHI, P. (2006), Unsustainable development to sustainable development: a conceptual model, International Journal Vol. 17 No. 6, 2006 pp. 654-672

GOUVEIA, J. SEAE investiga o cartel do cimento. Revista SIM. Brasil, 2010, Disponível em: <http://www.revistasim.com.br/asp/materia.asp?idtexto=1838>. Acesso em: 01 mai 2010.

GV Consult. Capacidade da infra-estrutura brasileira é inferior à média de sete países da América Latina. ABCR - Associação Brasileira de Concessionárias de Rodovias, 2004. Disponível em: <http:www.abcr.org.br>. Acesso em: 02 mar 2010.

HAYWARD, S., F 2005. "The China syndrome and the Environmental Kuznets Curve". Environmental Policy Outlook. Disponível em: <http://www.aei.org/publications/publD.23617>. Acesso em: 22 jun 2010.

IBGE - Instituto Brasileiro de Geografia e Estatística. Pesquisa Mensal de Emprego. Brasil, $2008 . \quad$ Disponível em: <HTTP:www.ibge.gov.br/home/estatistica/indicadores/trabalhoerendimento/pme_nova/defaul t.shtm>. Acesso em: 13 mai 2010.

INEA - Instituto Estadual do Ambiente. Regiões Hidrográficas do Estado do Rio de Janeiro. Rio de Janeiro, 2010.2 Disponível em: <http://www.inea.rj.gov.br/recursos/arquivos/RegioesHidrograficas.pdf>. Acesso em: 5 mai 2010.

JOHN, Vanderley. Reciclagem de resíduos na construção civil - contribuição à metodologia de pesquisa e desenvolvimento. São Paulo: Tese (livre docência) - Escola Politécnica, Universidade de São Paulo, 2000.

LEVY, Salomon. Reciclagem do entulho da construção civil, para utilização com agregados para argamassas e concretos. São Paulo: Dissertação de Mestrado - Escola Politécnica, Universidade de São Paulo, 1997.

MEADOWS, Donella H. Limits to Growth. New York: Penguin Group USA, 1972. 
PAPA, G. Repasse de materiais e reforma tributária prejudicam o mercado concreteiro. Canal do transporte. Brasil, 2003. Disponível em: $<\mathrm{http}: / / \mathrm{www}$.canaldotransporte.com.br/detalheopina. asp?id=108\%20\&\%20foto=N\%E3o>. Acesso em: 02 mai 2010.

PAULERA, P. SP: reciclagem de entulho de construção dá lucro. G1. Brasil, 2010, Disponível em: < http://jornalnacional.globo.com/Telejornais/JN/0,,MUL100504210406,00.html>. Acesso em: 02 jul 2010.

PINTO, Tarcísio. Metodologia para a gestão diferenciada de resíduos sólidos da construção urbana. São Paulo: Tese de Doutorado - Escola Politécnica, Universidade de São Paulo, 1999.

PORTER, M.E., Competitive Strategy, Free Press, New York, NY, 1980.

ROSA, R. Brasil pode acabar com pobreza extrema na próxima década, prevê Ipea. G1. Brasil, 2010, Disponível em: < http://g1.globo.com/economia-enegocios/noticia/2010/07/brasil-pode-acabar-com-pobreza-extrema-na-proxima-decadapreve-ipea.html>. Acesso em: 25 jul 2010.

SILVA, V.G. da. Avaliação da Sustentabilidade de Edifícios de Escritórios Brasileiros: Diretrizes e Base Metodológica. São Paulo: Tese de Doutorado - Escola Politécnica, Universidade de São Paulo, 2003.

SRIVASTAVA, S.K. e SRIVASTAVA, R.K. (2003), "How green are Indian firms", Productivity, Vol. 44 No. 2, pp. 294-302

TARUN, R. N. Sustainability of Concrete Construction. Pract. Periodical on Struct. Des. and Constr, Milwaukee, V. 13, n. 2, p. 98-103, 2008.

ULSEN, C. Técnica de reciclagem reduz volume de lixo na construção. G1. Brasil, 2010, Disponível em: <http://g1.globo.com/Noticias/Economia_Negocios/0,,MUL3013359356,00.html>. Acesso em: 02 jul 2010.

UNC - União Nacional da Construção. A construção do desenvolvimento sustentado. A importância da construção na vida econômica e social do país. São Paulo, 2006.

UNITED NATIONS - Division for Sustainable Development. UNCED, Earth Summit, Agenda 21 <http://www.un.org/esa/dsd/agenda21/> Rio de Janeiro, Brasil, 1992. Acesso em: 20 jun 2010.

VALVERDE, F. M. Balanço Mineral Brasileiro 2001 - Agregados para Construção Civil. Departamento Nacional de Produção Mineral. Brasil, 2001. Disponível em: <http:// http://www.dnpm.gov.br/assets/galeriadocumento/balancomineral2001/agregados.pdf>.

Acesso em: 20 jun 2010.

\footnotetext{
' Índice de Desenvolvimento Humano (IDH) é um índice criado pelo Programa das Nações Unidas para o Desenvolvimento Humano (PNUD). Este índice promove a comparação da qualidade de vida entre os países por meio de três fatores, em que o setor em estudo influencia diretamente: no conforto material, representado pelo PIB per capita; na expectativa de vida ao nascer e na possibilidade de desenvolvimento intellectual da população.
} 
' Global Reporting Initiative é um acordo internacional, criado com uma visão de longo prazo, multistakeholder, cuja missão é elaborar e difundir as diretrizes para organização de relatórios de sustentabilidade aplicáveis globalmente e voluntariamente.

' Índice de Sustentabilidade Empresarial da Bovespa é o índice composto somente por ações de empresas que se destacam em responsabilidade social e sustentabilidade, inspirado nas experiências internacionais.

' Balance Scorecard (BSC) metodologia de medição e gestão de desempenho desenvolvida pelos professores da Harvard Business School, Robert Kaplan e David Norton, em 1992. 